\title{
A Pesquisa Como Princípio Educativo: Em Busca De Caminhos Para Uma Educação Significativa E Emancipadora
}

Research as an educational principle: in search of ways to a meaningful and emancipating education

La investigación como principio educativo: en búsqueda de caminos para una educación significativa y emancipadora

ADELINE ARAÚJO CARNEIRO FARIAS ${ }^{1}$, JOCELAINE OLIVEIRA DOS SANTOS², IARA VANESSA MAFRA BICHARA ${ }^{3}$

${ }^{1}$ Instituto Federal de Sergipe/ campus Aracaju.

${ }^{2}$ Instituto Federal de Sergipe/campus Estância.

${ }^{3}$ Instituto Federal de Sergipe/ campus Aracaju.

\begin{abstract}
RESUMO: No presente artigo apresentamos as experiências e resultados alcancados a partir do desenvolvimento de uma pesquisa científica, realiz̨ada juntamente com estudantes do ensino médio, tendo por objetivos produziir conhecimentos que subsidiem transformações na educaşão, nos aproximando de uma educaşão democrática, participativa e emancipadora, a partir da execuşão e avaliação de projeto educacional pautado na metodologia ativa de educar através da pesquisa. A pesquisa teve por ancoragem teórica os entendimentos de John Dewey, Paulo Freire e Pedro Demo sobre a relevância da experiência e da pesquisa enquanto principio educativo, e ainda, nos entendimentos de Michel Thiollente René Barbier sobre a metodologia da pesquisa-asão. Enquanto resultados, destacamos as descobertas construídas durante o monitoramento as etapas do projeto, bem como as conclusões da análise ao final dos processos.

\section{EDUCAÇÃO SIGNIFICATIVA. ENSINO ATRAVÉS DA PESQUISA. METODOLOGIA ATIVA. METODOLOGIAS INOVADORAS. PROFESSOR PESQUISADOR.}

\begin{abstract}
In this article we present the experiences and results achieved from the development of a scientific research, carried out together with high school students, aiming to produce knowledge that subsidizes transformations in education, bringing us closer to a democratic, participatory and emancipatory education, starting from of the execution and evaluation of an educational project based on the active methodology of educating through research. The research had as theoretical anchor the understandings of John Dewey, Paulo Freire and Pedro Demo on the relevance of experience and research as an educational principle, and also, on the understandings of Michel Thiollent and René Barbier on the methodology of action research. As results, we highlight the findings built during the monitoring of the project stages, as well as the conclusions of the analysis at the end of the processes.
\end{abstract}

MEANINGFUL EDUCATION. TEACHING THROUGH RESEARCH. ACTIVE METHODOLOGY. INNOVATIVE METHODOLOGIES RESEARCHER.

The rights to publish this article are assigned to "Revista Internacional Educon" by the authors. The terms of a Creative Commons attribution 4.0 International (CC BY 4.0) are applied, which allows unrestricted usage, distribution and reproduction in any means if the source is correctly quoted. 
RESUMEN: En el presente artículo presentamos las experiencias y resultados logrados a partir del desarrollo de una investigación cientifica, realizada en conjunto con estudiantes de la enseñanza secundaria, teniendo como objetivo producir conocimientos que subsidien transformaciones en la educación, nos aproximando de una educación democrática, participativa y emancipadora, a partir de la ejecución y evaluación del proyecto educacional pautado en la metodología activa de educar por medio de la investigación. La investigación tubo por anclaje teórico los entendimientos de John Dewvey, Paulo Freire y Pedro Demo sobre la relevancia de la experiencia y de la investigación en cuanto principio educativo, y aún, en los entendimientos de Michel Thiollent y René Barbier sobre la metodología de la investigaciónacción. En cuanto resultados, destacamos las descubiertas construidas durante el monitoreo de las etapas del proyecto, bien como las conclusiones del análisis al final de los procesos.

EDUCACIÓN SIGNIFICATIVA. ENSEÑANZA A TRAVÉS DE LA PESQUISA. METODOLOGÍA ACTIVA. METODOLOGÍAS INNOVADORAS. PROFESOR INVESTIGADOR.

\section{Introdução}

A educação contribui de forma intencional no processo de construção pessoal e social da vida das pessoas. A edificação do ser humano passa pelo processo educativo, portanto, eis o papel social da educação. A humanização e desumanização, de acordo com Freire (1978) são possibilidades para o ser humano, enquanto seres inacabados e conscientes de sua inconclusão, e nesse sentido, cabe-nos, enquanto educadores, contribuir para o robustecimento permanente de paradigmas e conduções que coadunem com a humanização.

Cônscios desse compromisso pessoal e social que a docência demanda, é que desenvolvemos estudos e pesquisas, a partir das quais iniciamos nossos investimentos no sentido de construirmos uma bagagem teórica, bem como de experiências, que nos possibilitasse inserir atividades de pesquisa de forma integrada ao ensino, enquanto estratégia pedagógica, visando promover uma educação contextualizada e significativa para o estudantes. Desse modo, vimos pesquisando e executando projetos na direção de consolidar uma proposta de abordagem que tenha sucesso na integração da pesquisa ao ensino, tendo a pesquisa enquanto princípio científico e educativo (Demo, 2006).

Tais investimentos partem da compreensão de que quanto mais contextualizadas, significativas (Freire, 1985) e pautadas na abordagem do "aprender fazendo" (Dewey, 1971; 1979), atualmente muito divulgada como learn by doing, maior será a qualidade do conhecimento construído.

Encetando do contexto educacional, elaboramos e desenvolvemos um projeto de pesquisa, que fora executado durante o ano 2019, que teve por intencionalidade conhecer a adesão dos estudantes a práticas educativas pautadas na integração do ensino com a pesquisa, visando contribuir para a melhoria da qualidade do processo de ensino e aprendizagem. Na perspectiva de contribuição político-social, nos motivamos diante da oportunidade de produzir conhecimentos que possam vir a subsidiar transformações qualitativas na Educação, no sentido de aproximação de uma educação democrática, participativa e emancipadora.

Nesse intento, desenvolvemos a pesquisa ao longo do ano letivo 2019, junto a três turmas que apresentaremos a seguir, utilizando a pesquisa-ação como metodologia qualitativa.

Nesse artigo, apresentamos o mencionado projeto e seus resultados, cientes que as (in) conclusões as quais chegamos, são pontos de partida para a prossecução de futuros projetos. 


\section{Diagnóstico do contexto e desenho da problemática do projeto}

O presente projeto foi idealizado a partir de inquietações pessoais e profissionais que emergiram ao longo de quase duas décadas de atuação enquanto professora/pesquisadora. A persistência da concepção bancária na Educação e suas consequências, tem sido o combustível para as apreensões que nos impulsionam a não estacionar em zonas de conforto da mesmice, que fragiliza a formação do discente, restringindo sobremaneira as infinitas possibilidades que uma educação emancipadora propiciaria.

No decorrer dos processos de formação profissional, bem como do amadurecimento da crítica à prática educativa cotidiana, fomos nos identificando com propostas de atuação que se afiguravam como possibilidades de aprimoramento, às quais formos investindo em experimentos com momentos de avanços e recuos. Dentre estas experiências, investimos em metodologia ativa com ênfase na integração da pesquisa ao ensino, com base na pesquisa como princípio pedagógico, no aprender fazendo e na aprendizagem contextualizada e significativa.

Entretanto, urgiu submeter estas práticas ao escrutínio do método científico, com a intenção de verificar as percepções dos estudantes sobre tais práticas, avaliando cada etapa dos processos, com vistas a que os resultados da pesquisa nos possibilite melhorar e/ou reconduzir nossas práticas.

Nesse intento, no ano 2018 nos propusemos a desenvolver um projeto de pesquisa e elaboramos o mesmo, sendo este executado ao longo do ano 2019. O contexto de construção e execução do projeto de pesquisa é composto pela realidade de uma instituição de educação, voltada à formação profissional, que oferta desde cursos de formação inicial e continuada à pós-graduação: o Instituto Federal de Educação, Ciência e Tecnologia de Sergipe, no campus Aracaju. Tendo identificado práticas vinculadas ao paradigma da educação bancária nos diferentes níveis e modalidade de ensino ofertados, dentro desse universo, definimos como população três turmas do curso técnico em química integrado ao ensino médio. Desse modo, o projeto fora desenhado tendo em consideração o cenário da formação profissional de nível médio, ofertada para jovens adolescentes, em regime de educação integral.

Assim sendo, participaram do projeto uma turma de cada série do ensino médio, primeiro, segundo e terceiro ano, portanto. A escolha desse curso, deu-se por motivações da pesquisadora já ter contato com os estudantes do segundo e terceiro ano, conhecendo previamente algumas dificuldades dos mesmos, relacionadas à carga horária de aulas e atividades extenuante, bem como em relação ao arrefecimento dos alunos para parte das aulas, em especial aquelas que, de modo geral, se apresentam muito teóricas, e como eles dizem, são "decorebas", perdendo o sentido para o esforço do aprendizado. E sobre esse ponto, concordamos com as percepções dos estudantes, posto que:

[...] Por isso também é que ensinar não pode ser um puro processo, como tanto tenho dito, de transferência de conhecimento do ensinante ao aprendiz. Transferência mecânica de que resulte a memorização maquinal que já critiquei. Ao estudo crítico corresponde um ensino igualmente crítico que demanda necessariamente uma forma crítica de compreender e de realizar a leitura da palavra e a leitura do mundo, leitura do contexto (Freire, 2001, p. 264).

Foi nesse contexto e a partir desses inquietantes entendimentos que elaboramos como problemática de pesquisa as seguintes questões: $\mathrm{O}$ desenvolvimento do ensino que tenha a pesquisa como princípio pedagógico, torna o conhecimento construído significativo para o estudante? Essa metodologia pode se configurar como alternativa viável para a melhoria da qualidade do processo de ensino e aprendizagem? 


\subsection{Educar pela pesquisa: desenho de uma problemática de pesquisa}

Todas as profissões, sendo desenvolvidas no contexto da sociedade que não é estática, sofrem transformações necessárias para atender às demandas hodiernas. A prática docente não pode ser diferente. O paradigma da educação tradicional ainda se mantém em evidência, apesar de várias críticas ao mesmo. Todavia, cabe precisar que tal padrão de fazer educação, não apenas concorreu para o que veio a se constituir enquanto prática educacional formal, mas também favoreceu a arquitetura de novos modelos e propostas posteriores, através da crítica ou do melhoramento.

Ressaltamos que mesmo esse artigo se tratando sobre um projeto de pesquisa que avalia a implementação de uma metodologia ativa na educação básica formal, partimos de uma crítica ciente do contexto de surgimento e legado da escola tradicional, que se impõe a partir da implantação dos sistemas nacionais de ensino, sob a égide da sociedade burguesa, sob influência de uma classe emergente, cujo ideário consolidou o discurso da educação enquanto direito de todos e dever do Estado, numa sociedade democrática. (Saviani, 1991). Dito isso, para nos situar no panorama internacional, não custa ressaltar que que a universalização da educação ainda não é uma realidade em muitas partes do mundo, e mesmo em países onde já conta com amparo legal, não se faz de forma igualitária, como podemos observar no Brasil e no estado de Sergipe, pois conforme analisa Gadotti (1995) “(...) uns receberam mais educação do que outros.".

Partindo dos interesses de classe que fundam o ensino tradicional, pautamos a nossa crítica e nos sentimos impulsionados a buscar caminhos para adequar nossa prática educativa à formação de atores sociais capazes de reconhecer seu espaço no Estado de direito. Para tanto, focalizamos a justificativa da presente investida, a partir da necessidade expressa de repensar, desconstruir e reconstruir sob novas bases o do modus operandi em vigor na educação formal, de forma predominante. Tal percepção é compartilhada por diversos estudiosos da área da educação, dentre os quais pontuamos:

O iluminismo educacional representou o fundamento da pedagogia burguesa, que até hoje insiste, predominantemente na transmissão de conteúdos e na formação social individualista. A burguesia percebeu a necessidade de oferecer instrução, mínima, para a massa trabalhadora. Por isso, a educação se dirigiu para a formação do cuidado disciplinado. (Gadotti, 1995. p.90)

(...) atribui-se ao sujeito um papel irrelevante na elaboração e aquisição do conhecimento. Ao indivíduo que está adquirindo conhecimento compete memorizar definições, enunciados de leis, sínteses e resumos que lhe são oferecidos no processo de educação formal a partir de um esquema atomístico. (Mizukami, 1986. p.11)

Localizamos a mencionada problemática no contexto de uma sociedade na qual as relações e processos com características de liquidez e ambivalência, conforme anuncia Bauman em seu estudo sobre a educação e a juventude. $\mathrm{O}$ autor nos adverte quanto a oferta de uma educação, desenvolvida de modo descontextualizo, fortemente assinalado pelos estudantes como prescindível e sem sentido:

O nível mais baixo é a transferência de informação a ser memorizada. O segundo, a "deuteroaprendizagem", visa ao domínio de uma "estrutura cognitiva" à qual a informação adquirida ou encontrada no futuro possa ser absorvida e incorporada. Mas há também um terceiro nível, que expressa a capacidade de desmontar e reorganizar a estrutura cognitiva anterior ou desembaraçar-se totalmente dela, sem um elemento substituto. Esse terceiro nível foi visto por Bateson como um fenômeno patológico, antieducativo mesmo. (Bauman, 2012, p. 17).

Nessa conjuntura, a partir de estudos e compartilhamento de experiências com outros profissionais de educação, definimos por experimentar o desenvolvimento de uma prática docente pautada por metodologia ativa, sobre a qual explanaremos adiante. 
Partindo da problemática de pesquisa já mencionada, elaboramos as diretrizes da pesquisa e seus objetivos, sempre tendo por foco as estratégias da pesquisa-ação, especialmente no que se refere a:
A ação educacional a ser estudada e estimulada pela pesquisa-ação deve contribuir para transformar processos, mentalidades, habilidades e promover situações de interação entre
professores, alunos e membros do meio social circundante. (Thiollent; Colette, 2014, p. 212)

Desse modo, definimos como diretrizes para o projeto de pesquisa o alinhamento da execução aos princípios das propostas de metodologias ativas, considerando o ensino pela pesquisa enquanto tal, sendo estes:

- A centralidade do processo de aprendizagem nos estudantes;

- A adoção da postura do professor enquanto mediador/facilitador do processo de ensino e aprendizagem;

- O respeito a autonomia do estudante durante o processo de construção do conhecimento;

- A adoção da reflexão crítica;

- A problematização da realidade;

- A adoção do trabalho em equipe;

- A busca pela inovação.

Nesse sentido, os objetivos do projeto foram:

Objetivo Geral:

Produzir conhecimentos que possam vir a subsidiar transformações qualitativas na Educação, no sentido de aproximação de uma educação democrática, participativa e emancipadora, a partir da execução e avaliação de projeto educacional pautado na metodologia ativa de educar através da pesquisa.

Objetivos específicos:

- Realizar atividades educacionais pautadas na pesquisa como princípio pedagógico, com vistas a verificar sua viabilidade em turmas do ensino médio;

- Executar projetos de pesquisa ancorados na metodologia da pesquisa-ação;

- Conhecer as percepções dos estudantes participantes da pesquisa acerca da metodologia ativa executada.

\section{Desenho metodológico do projeto}

Para aprender não basta escutar; urge pesquisar e elaborar. (Demo, 1998, p. 11)

Nessa etapa do artigo, apresentamos dois aspectos fundamentais do projeto: o referencial teórico, ou seja, as construções teóricas que dão fundamento científico à pesquisa, e descrevemos os procedimentos técnicos adotados para a execução da pesquisa.

\subsection{Construções teóricas: principais aportes à pesquisa}

No processo de definição do arcabouço teórico, envidamos esforços em dispor e articular algumas concepções, objetivando a granjear o melhor avizinhamento à realidade, de maneira a nos propiciar processos de análises, capazes de obstaculizar conclusões simplistas e reducionistas que ocultam contradições. Com este fito, partimos de um direcionamento teórico, que engendra possibilidades de paralelos e composições teóricas, capazes de nos assegurar a apreensão de matizes da realidade em estudo. 
Desse modo, organizamos um apanhado de percepções de quatro autores, que ao longo de nossos estudos e práticas, tem se mostrado profícuo, sendo estes:

i. Os entendimentos de Pedro Demo (1998, 2009) sobre a importância de "Educar pela pesquisa". Conforme Pedro Demo, todo professor deve, por regra, ser um pesquisador. É uma condição imprescindível para a percepção da pesquisa como princípio pedagógico, que irá favorecer a harmonização entre a teoria e a prática, dando sentido ao processo de construção de conhecimentos, como o autor defende em várias obras, das quais destacamos os excertos que seguem:

Considero imprescindível aliar teoria e prática, ainda que isso seja particularmente difícil na academia, que analisa problemas, não os enfrenta. A "grade" curricular se consome em discursos e aulas que definem, categorizam, classificam, avaliam, ordenam, sobretudo memorizam e reproduzem conceitos e teorias, sem compromisso com mudar a realidade, como se teorias da realidade fossem mais importantes que a própria realidade. (...) Aprender exige pesquisa, elaboração e produção próprias, autoria individual e coletiva, participação ativa, virtudes que as pedagogias e as licenciaturas não praticam ou desfiguram, em geral por conta de seus professores não autores. Entendo que sem pesquisa não pode haver aula: vai ser mera cópia. (Demo, 1998, p.7 - 9)

O papel do professor é organizar o trabalho produtivo do aluno, com problematizações atrativas e realistas dos conteúdos curriculares, de sorte que ele, em vez de frequentar aula, pesquise sob orientação docente. Necessita-se de professor-autor, uma habilidade que é imprescindível para problematizar com qualidade visível: transformar conteúdos curriculares em problemas pertinentes e interessantes. (Demo, 1998, p.13)

Segundo Demo (2009), dentre os empreendimentos que possibilitam o aprimoramento da educação, ou seja, "iniciativas que aprimoram a oportunidade de aprender bem” (p.14), se destacam, dentre outros, as metodologias pedagógicas pautadas pela problematização da realidade, a avaliação processual e a educação pela pesquisa.

ii. As concepções de Paulo Freire (1983, 1985, 1992, 1997, 2001) acerca da importância da educação significativa, contextualizada, portanto pautada pela centralidade no aluno. Encontramos a viabilidade da articulação entre os entendimentos de Freire e Demo, a partir da contextualização do processo de construção do conhecimento, para torná-lo significativo, a partir da experiências da vivência do estudante, estabelecendo uma conexão entre o experienciado e a relevância de conhecimentos conceituais, atitudinais, procedimentais e factuais necessários ao estudante, para uma abordagem crítica à realidade. Destacamos ainda, a importância da pesquisa, nos entendimentos de Freire, conforme apontamos nos trechos em seguida:

[...] toda a docência implica pesquisa e toda pesquisa verdadeira implica docência. Não há docência verdadeira em cujo processo não se encontre a pesquisa como pergunta, como indagação, curiosidade, criatividade, assim como não há pesquisa cujo andamento necessariamente não se aprenda porque se conhece e não se ensine porque se conhece e não se ensine porque se aprende (Freire, 1992, p. 192-193).

[...] educação é comunicação, é diálogo, na medida em que não é transferência de saber, mas um encontro de sujeitos interlocutores que buscam a significação dos significados. (Freire, 1983, p. 69).

Nesse sentido, consideramos as ideias do autor pertinentes para amparar teoricamente a pesquisa proposta, visto que em toda a sua obra, Freire (2001, p. 264) arrazoe sobre que ensinar não se reduza a um mero processo de "transferência de conhecimento do ensinante ao aprendiz", mas que faz-se imprescindível uma postura crítica para realizar "a leitura da palavra e a leitura do mundo".

iii. Utilizamos ainda as produções de John Dewey (1959, 1971) acerca da proficuidade da experiência no processo educativo. Conforme o autor, uma atividade educativa pautada na experiência, 
tem potencial para despertar a curiosidade necessária para avigorar disposições fundamentais para buscar resoluções e produzir conhecimentos marcados pela significância, e assim sendo, "cada experiência é ima força em marcha”. (Dewey, 1971, p.29).

Na obra de Dewey, nos importa focar na relevância da experiência, no sentido da oportunidade dos estudantes alcançarem o entendimento da conexão teoria-prática, produzindo conhecimentos relacionais, cujas aplicações não se restrinjam a exigências protocolares da educação formal, mas que transcendam a estas, importando para o entendimento de sua atuação e relações estabelecidas na realidade social de modo abrangente, como melhor explica o próprio autor:

\footnotetext{
'Aprender da experiência' é fazer uma associação retrospectiva e prospectiva entre aquilo que fazemos às coisas e àquilo que em consequência essas coisas nos fazem gozar ou sofrer. Em tais condições a ação torna-se uma tentativa; experimenta-se o mundo para se saber como ele é; o que se sofrer em consequência torna-se instrução - isto é, a descoberta das relações entre as coisas. (Dewey, 1959b, p.153).
}

Com vistas a fundamentar o desenvolvimento da pesquisa, no que tange aos procedimentos técnicos de coleta e análise dos dados, ancoramos o projeto nas produções de Thiollent e Barbier (2014) relativamente a pesquisa-ação. Consideramos que a pesquisa-ação seja a metodologia que melhor nos oportuniza observar e avaliar a pesquisa durante a execução do projeto de pesquisa, possibilitando aperfeiçoamento no decorrer do desenvolvimento, bem como, tal metodologia se alinha à proposta pedagógica do projeto, como os mencionados autores referenciais, clarificam na sequência:

[...] a pesquisa-ação é um tipo de pesquisa social com base empírica que é concebida e realizada em estreita associação com uma ação ou com a resolução de um problema coletivo e no qual os pesquisadores e os participantes representativos da situação ou do problema estão envolvidos de modo cooperativo ou participativo (Thiollent, 2009, p. 16).

A pesquisa-ação obriga o pesquisador de implicar-se. Ele percebe como está implicado pela estrutura social na qual ele está inserido e pelo jogo de desejos e de interesses de outros. Ele também implica os outros por meio do seu olhar e de sua ação singular no mundo. (Barbier, 2002, p.14).

Nessa perspectiva, a pesquisa-ação nos possibilitou executar o experimento no mundo real, a partir de intervenções do pesquisador, nas quais os participantes tem papéis ativos, e assim sendo, as situações planejadas vão se modificando a partir do fazer coletivo, e desse movimento de observação e avaliação, assim como da emersão de resistências e contratempos, vamos edificando conhecimentos. (Thiollent, 2009, p. 21/22)

\subsection{Procedimentos Técnicos da pesquisa}

Desta feita, apresentamos na sequencia os procedimentos técnicos voltados à coleta dos dados primários e sua análise. Para tanto, detalharemos a seguir os critérios utilizados para definição dos participantes, as técnicas e procedimentos adotados para coleta de dados, assim como para a análise.

Os participantes da pesquisa foram definidos a partir de experiências anteriores da pesquisadora, que contaram com uma convivência prévia com a maior parte dos estudantes envolvidos no projeto. Nessa oportunidade, durante as atividades diagnósticas e avaliativas, evidenciou-se o desânimo e cansaço dos estudantes em relação as aulas, sob vários aspectos, todavia, observamos uma exaltação direcionada à crítica a metodologia adotada pelos docentes, de modo geral. Os adjetivos utilizados nessas oportunidades pelos estudantes, referindo-se a forma como a maior parte das aulas são desenvolvidas se concentraram em: enfadonhas, cansativas, repetitivas e desestimulante. 
Assim, no início do ano letivo 2019, apresentamos a proposta do projeto para as turmas de $1^{\circ}, 2^{\circ}$ e $3^{\circ}$ s anos do curso técnico em química integrado ao ensino médio, do IFS/campus Aracaju, e obtivemos a adesão desejada. Nesse sentido, é relevante ressaltar, que o projeto fora desenvolvido em concomitância as atividades educacionais do desenvolvimento da componente curricular "Sociologia", ofertadas em todos os anos do ensino médio envolvidos na pesquisa, tendo em vista os objetivos do projeto, alinhados com o referencial:

No processo de educação associado a essa proposta metodológica, a relação entre pesquisa (fase de investigação) e a ação educacional pode ser de tipo sequencial. Primeiro, os grupos pesquisam o contexto de atuação, os atores, suas identidades, necessidades e expectativas. Com base nesse levantamento, estabelece-se a programação de uma ação educacional que é ponto de partida para outras investigações retroativas. (Thiollent; Colette, 2014, p. 211)

Então, os participantes tem por perfil serem jovens com idades entre 15 e 20 anos, distribuídos em três turmas já mencionadas, que juntas perfizeram um total de 92 participantes. As atividades planejadas para a pesquisa foram compostas por elaborações participativas de projetos de pesquisa, sobre problemas sociais definidos a partir do interesse dos participantes. Os estudantes foram agrupados em equipe, conforme a afinidade dos problemas sociais pretendidos para estudo. Foram elaborados projetos de pesquisa, tendo por modelo o roteiro institucional do programa de iniciação científica (PIBIC). Elaborados os projetos, foi realizada a pesquisa, aplicado o tratamento aos dados coletados por cada equipe, e findo essa etapa, realizamos a divulgação cientifica das descobertas para a comunidade acadêmica, a partir da exposição de pôsteres.

A cada etapa foram realizados momentos de problematização acerca das mesmas, refletindo sobre os caminhos percorridos e os que viriam a seguir, de modo que fomos avaliando e ajustando o processo de construção durante a execução. De forma mais detalhada, pontuamos na sequência, na Tabela 1, cada etapa do planejamento, da implementação, do monitoramento e avaliação do projeto, considerando a metodologia da pesquisa-ação implementada.

Ao desenharmos o passo a passo desse planejamento, nos guiamos pelas orientações de Thiollent no que concerne a flexibilidade da pesquisa-ação, conforme o autor nos indica:

O planejamento de uma pesquisa-ação é muito flexível (...) não segue uma série de fases rigidamente ordenadas. Há sempre um vaivém entre várias preocupações a serem adaptadas em função das circunstâncias e da dinâmica interna do grupo de pesquisadores no seu relacionamento com a situação investigada. (2009, p.51).

Tabela 1 - Atividades desenvolvidas no projeto, distribuídas por etapas e períodos de execução.

\begin{tabular}{|c|c|c|}
\hline ETAPA & ATIVIDADES & $\begin{array}{l}\text { PERÍODO DE } \\
\text { EXECUÇÃO }\end{array}$ \\
\hline \multirow{4}{*}{$1^{\mathrm{a}}$} & $\begin{array}{l}\text { Definição de problemas sociais para estudo, partindo das } \\
\text { significâncias das temáticas para os participantes. }\end{array}$ & \multirow{4}{*}{$1^{\circ}$ bimestre $/ 2019$} \\
\hline & $\begin{array}{l}\text { Agrupamento dos participantes por afinidade de } \\
\text { interesses. }\end{array}$ & \\
\hline & Estudo de textos acerca dos problemas sociais definidos. & \\
\hline & $\begin{array}{c}\text { Monitoramento da execução da etapa (dinâmicas em } \\
\text { grupo, observação, coleta de relatos) }\end{array}$ & \\
\hline \multirow{4}{*}{$2^{\mathrm{a}}$} & Definição do problema de pesquisa. & \multirow{4}{*}{$2^{\circ}$ bimestre/2019 } \\
\hline & $\begin{array}{c}\text { Elaboração dos objetivos da pesquisa, a partir do } \\
\text { problema de pesquisa. }\end{array}$ & \\
\hline & $\begin{array}{c}\text { Monitoramento da execução da etapa (dinâmicas em } \\
\text { grupo, observação, coleta de relatos) }\end{array}$ & \\
\hline & Elaboração da metodologia da pesquisa & \\
\hline
\end{tabular}




\begin{tabular}{|c|c|c|}
\hline \multirow{3}{*}{$3^{a}$} & Coleta dos dados & \multirow{3}{*}{$3^{\circ}$ bimestre $/ 2019$} \\
\hline & Análise dos dados & \\
\hline & $\begin{array}{c}\text { Monitoramento da execução da etapa (dinâmicas em } \\
\text { grupo, observação, coleta de relatos) }\end{array}$ & \\
\hline \multirow{4}{*}{$4^{a}$} & $\begin{array}{c}\text { Elaboração de meio para divulgação científica dos } \\
\text { conhecimentos construídos (Pôster) }\end{array}$ & \multirow{4}{*}{$4^{\circ}$ bimestre $/ 2019$} \\
\hline & $\begin{array}{l}\text { Exposição e debate sobre os problemas sociais } \\
\text { pesquisados e resultados dos projetos das equipes. }\end{array}$ & \\
\hline & $\begin{array}{c}\text { Monitoramento da execução da etapa (dinâmicas em } \\
\text { grupo, observação, coleta de relatos). }\end{array}$ & \\
\hline & Avaliação final do projeto por todos os envolvidos. & \\
\hline
\end{tabular}

Fonte: Elaborada pelas autoras. 2020.

Para a coleta dos dados dos projetos de pesquisa elaborados pelos estudantes, optamos por concentrarmos em apenas duas técnicas, tendo em vista o volume de trabalho envolvido no acompanhamento a todas as equipes, das três turmas, desse modo, trabalhamos com a realização de entrevistas ou com aplicação de formulários eletrônicos, a depender da melhor adequação os objetivos de cada projeto.

Ao final de cada etapa, foram realizadas atividades visando ao monitoramento das mesmas, cumprindo uma programação composta por dinâmicas em grupo, oportunidade nas quais os estudantes relatavam e debatiam sobre o andamento de seus projetos, compartilhando experiências e destacando avanços, dificuldades e aprendizados de cada atividade realizada. Nestas intervenções foram registradas em diário as observações realizadas pela pesquisadora.

Ao final da última etapa, cumpridas todas as atividades previstas, realizamos um processo de avaliação final, na intenção de obtermos uma visão do processo como um todo, capturando as percepções dos participantes, de modo a verificarmos o alcance ou não dos objetivos propostos no projeto.

\section{Aprendizados do/em processo}

Ao finalizarmos o projeto de pesquisa, em dezembro do ano 2019, fomos assolados por uma miscelânea de emoções, que oscilaram entre a melancolia do término de uma atividade gratificante, a sensação do dever cumprido pelas descobertas alcançadas durante o processo. Entretanto, pairando entre essas sensações, foi se estabelecendo a convicção de estarmos diante de um trabalho que sempre estará inconcluso, diante de tantas possibilidades que se apresentam a partir da análise dos resultados alcançados. Esta sensação fica ainda mais intensa, quando vislumbramos a riqueza das produções construídas, e o quanto ainda podem reder em conhecimentos, cada etapa do projeto realizada, cada dinâmica em grupo e debate, sem falar da copiosidade das vivências trazidas pelas interações com os participantes da pesquisa.

Inspirados nesse cenário, não nomeamos esse item final do artigo com a palavra "conclusão", tão usual, posto que, apesar de apresentarmos a seguir as conclusões a que chegamos ao final do projeto, estamos resolutos sobre a condição de continuidade e aperfeiçoamento, em trabalhos futuros.

Desse modo, destacaremos os resultados alcançados, de modo pontual, sintetizando nossas conclusões diante de dois aspectos principais que constituíram os objetivos da pesquisa:

1. Sobre a viabilidade da adoção da pesquisa como princípio educativo, enquanto metodologia ativa, no ensino médio;

2. Sobre a avaliação dos estudantes participantes, em relação a metodologia utilizada.

Para o desenvolvimento do projeto, enfrentamos desafios, alguns previsíveis e outros nem tanto. Dentre os previstos, salientamos a insegurança inicial dos estudantes em aderir ao projeto na condição 
de participantes. Suas hesitações repousavam no desconforto de avançar por caminhos desconhecidos. Temiam não conseguir fazer as atividades propostas, bem como não aprender o suficiente, colocando em risco seus resultados escolares ao final do ano letivo, evidenciando a necessidade de investimento também nas competências sociemocionais. (OCDE, 2015; p. 1)

Situamos essa situação no contexto da influência da escola ainda sob a égide do paradigma tradicional, o qual na crítica de Freire (2001) o ato de ensinar se resume a um processo de "transferência de conhecimento do ensinante ao aprendiz", que dar-se de forma mecânica, visando quase sempre na mera memorização. Portanto, diante do desafio de participar de forma autoral, assumindo um protagonismo no processo de aprendizado, não nos surpreendeu esta reação dos estudantes. (Silva e Porto, 2019, p.239).

Todavia, ficou claro que o fato de propomos a que os estudos partiriam de problemas sociais que fossem definidos a partir dos interesses deles, observamos, aos poucos, essa insegurança inicial ir se transformando em entusiasmo e confiança. Cremos também, que ao assumirmos uma postura educativa de mediadores, rompendo com a relação de poder historicamente posta, do foco do processo ser centralizado na figura do professor, fomos favorecendo a que os estudantes fossem paulatinamente assumindo a postura de participantes ativos.

Daí, se revela a descoberta de que o fato do professor/pesquisador ter apreendido uma concepção emancipadora de educação, e conseguir implementar em suas práticas e interações com os estudantes, faz-se imprescindível para que os estudantes saiam da postura defensiva e insegura, e acreditem no seu potencial criativo, seguros da mediação docente adequada. Portanto, como acentua Demo (1998, p.2) "O professor precisa, antes de tudo, aprender bem, e portanto, levar o aluno a aprender bem.”. Suplantadas as inquietações, os participantes definiram as problemáticas para seus projetos, comprovando a pluralidade de interesses e ilimitadas perspectivas de abordagem sobre realidade. Foram os problemas sociais escolhidos:

Temas selecionados pelas turmas do $1^{\circ}$ ano:

- Intolerância religiosa;

- Consumismo;

- Déficit de leitura nos jovens;

- Acessibilidade para pessoas com deficiência física na escola;

- Degradação Ambiental;

- Xenofobia;

- A Síndrome do Pensamento Acelerado(SPA);

- Violência doméstica;

- Violência contra os jovens.

Temas selecionados pelas turmas do $2^{\circ}$ ano:

- Dificuldades de acesso às oportunidades de emprego pelos deficientes auditivos;

- Desemprego e consequências sociais;

- Desvalorização da carreira científica;

- Desemprego dos jovens;

- Precariedade do sistema de saúde pública;

- Violência contra a mulher;

- Violência contra a juventude;

- Suicídio entre jovens;

- Bullying.

Temas selecionados pelas turmas do $3^{\circ}$ ano:

- Colonização Cultural;

- A ansiedade na juventude; 
- Fake News;

- Falta de reconhecimento da cultura local;

- Ditadura dos padrões de Beleza;

- Corrupção na política;

- Bifobia.

\section{4. (In) Conclusões de uma pesquisa na área da Educação}

No presente artigo, tratamos sobre os processos vivenciados no decorrer da execução de um projeto de pesquisa, sobre a utilização de metodologia ativa focada na pesquisa como princípio pedagógico, junto a estudantes do ensino médio integrado a educação profissional, bem como nos resultados alcançados, cujos principais achados abordamos nessa última parte do artigo.

Nessa conclusão do artigo, não temos a pretensão de dar por encerrada uma discussão tão significantemente laboriosa, além do que partimos da convicção do caráter icognoscível da realidade social, decorrente da sua permanente mudança, e por isso, a nomeamos de (in) conclusões, no sentido de que, não obstante o presente artigo apresente resultados de uma pesquisa sobre a temática educacional pretendida, este breve trabalho está ábdito de dar conta da complexidade e riqueza de tal questão.

A análise do dados coletados durante a pesquisa, nos possibilitaram verificar algumas situações que acreditamos terem sido favorecidas pelo caráter prático da metodología da pesquisa. Uma dessas situações é a necessidade de levar em consideração os diferentes níveis de maturidade escolar e de desenvolvimento humano peculiar aos alunos nas diferentes turmas. Posto que, identificamos maior facilidade para selecionar e interpretar criticamente textos e científicos e jornalísticos, entre os participantes do último ano, em relação aos do primeiro ano do ensino médio, com algumas exceções pontuais. Esta situação identificada durante o monitoramento, demonstrou a necessidade de adequação do nível de complexidade e exigência solicitado, em relação ao ano do ensino médio.

Porém, também se revelou que esse entendimento não deve ser generalizado, pois tal achado não deve ser generalizado, dispensando o diagnóstico prévio da turma envolvida, muito menos um acompanhamento cuidadoso aos grupos de trabalho, sem perder de vista ainda, as peculiaridades de seus integrantes, pois registramos ocorrências particulares em que equipe do primeiro ano demonstraram mais habilidade e autonomia para realizar determinada atividade, que a média das equipes da sua turma. Assim como, localizamos equipes do último ano do ensino médio que apresentaram mais dificuldade de adesão e execução dos projetos de pesquisa, do que equipes do primeiro ano.

Constatamos que o fato de adotarmos metodologia que muda a centralidade do processo de construção do conhecimento da figura do professor/pesquisador para o estudante/participante, gerou momentos de desorientação em algumas equipes, posto que visivelmente os participantes compreendiam o processo e atividades integrantes desse, sabiam o que fazer, mas ficavam temerosos de tomar a iniciativa, ou de propor uma forma diferente para encaminhar alguma solução de problema. Quando detectamos e levamos a situação para o debate coletivo, verificamos que esse temor tinha duas motivações principais: preocupação em não respeitar a autoridade do professor/pesquisador e medo de errar.

Observamos que estas situações são engendradas por um contexto cultural educacional, que ainda exalta a restrição da criatividade como estratégia pacificadora dos instintos, castrando potenciais e produções autorais. Assim sendo, é fundamental que o professor/pesquisador compreenda criticamente a realidade na qual intervêm, para evitar a reprodução das relações de poder assimétricas e frustram talentos e aptidões.

A escola não consegue aumentar a capacidade de compreender - inestimável resultado educativo - principalmente porque se esquece de promover as condições a ser ativamente usadas como meio de realizar consequências, de promover projetos que estimulem a inventiva 
e o engenho dos alunos, para que estes proponham objetivos a conseguir, descubram meios de levar a efeito as consequências pensadas [...] Muitos dos assim chamados "problemas", na verdade tarefas marcadas, demandam, quanto muito, uma espécie de habilidade mecânica na aplicação de regras estabelecidas e na manipulação de símbolos (Dewey, 1959, p.149).

Mais uma vez, vivenciamos os limites impostos pela cultura da educação tradicional, na qual todo o processo circula em torno da autoridade pessoal e acadêmica do professor, sendo esta postura intimidadora e desfavorecedora da emancipação do estudante como cidadão e ser humano, e ao mesmo tempo, é perversa para com o próprio educador, posto que perca oportunidades únicas de aperfeiçoar seus conhecimentos e práticas, como nos elucidam os autores abaixo:

(...) ao limitar a curiosidade do aluno, a sua expressividade, o professor autoritário limita a sua também. Muitas vezes, por outro lado, a pergunta que o aluno, livre para fazê-la, faz sobre um tema, pode colocar ao professor um ângulo diferente, do qual lhe será possível aprofundar mais tarde uma reflexão mais crítica. (Freire; Faundez, 1985, p. 23)

A cada etapa do projeto, realizamos atividades de monitoramento que reforçaram a avaliação de processo oriunda da observação e registros cotidianos. Ao final do projeto, também foi realizada uma avaliação coletiva mais incisiva sobre as percepções dos participantes acerca da metodologia desenvolvida durante o ano letivo.

Os produtos desses processos avaliativos demostram que:

- Quase a integralidade dos participantes concluiu que a utilização da pesquisa como estratégia de ensino facilitou o aprendizado pois tornou o processo mais interessante e provocativo;

- Destacou-se que as pesquisas, debates coletivos, exposições em equipes são mais estimulantes que aulas expositivas;

- Os participantes destacaram que ficou mais fácil e agradável estudar Sociologia a partir de pesquisas sobre temas atuais;

- Os participantes perceberam que os conceitos que estudaram em Sociologia, a partir da pesquisa, tem relação com conhecimentos de outras disciplinas que antes não concebiam que houvesse alguma conexão;

- Essa percepção levou a outra, de que seria ainda mais interessante e produtivo se o projeto de pesquisa envolvesse não apenas Sociologia, mas também outras disciplinas e áreas de conhecimento;

- Foi um consenso que participar da decisão sobre os problemas sociais que seriam pesquisados, portanto ter um papel atuante no processo, foi fundamental para suas motivações durante todo o ano letivo.

Algumas colocações dos estudantes durante os momentos de avaliação do projeto, reforçam as descobertas pontuadas acima, e demostram o interesse dos estudantes em abordagens inovadoras:

A pesquisa ajuda muito com o aprendizado, a gente não fica naquela coisa automática que é boa parte das aulas. O tema livre nos dá a oportunidade de pesquisar sobre algo que queremos aprender ou sobre algo que é importante nos dias atuais mas não tem muita visibilidade. $\mathrm{O}$ estudo através de pesquisa é uma excelente forma de aprendizado que eu gostaria que continuidade no próximo ano letivo. (Participante A23, $3^{\circ}$ ano)

Eu quero sugerir que a senhora continue com a metodologia e tente se aliar a outras matérias (como as de Humanas). Me ajudou a aprender o conteúdo sem o estresse da avaliação comum, com provas, trabalhos gigantes, cansativos e tal. (Participante C06, $2^{\circ}$ ano) 
Foi uma excelente experiência, pois além de promover uma exposição para toda a escola, ainda proporcionou aprendizado. Ficou fácil entender a relação entre o conteúdo abordado em sala e os estudos sobre os problemas escolhidos, e isso me ajudou a ter uma melhor fixação dos assuntos de Sociologia através de uma maneira mais atrativa. (Participante B16, $2^{\circ}$ ano)

Foi uma experiência legal, embora tenha sido trabalhoso, aprendemos bastante. Eu não imaginava que fazer pesquisa poderia ser tão legal. Eu aprendi Sociologia e mais um monte de coisas. (Participante A21, $1^{\circ}$ ano)

A partir do exposto, (in)concluímos esse artigo, através do qual almejamos contribuir na construção de conhecimentos e fortalecimento dos debates acerca da viabilidade da adoção da pesquisa como princípio pedagógico.

Ansiamos que a divulgação destes conhecimentos possa se converter em subsídios para demais professores/pesquisadores, e que possamos, juntos, construir novos paradigmas pautados numa educação significativa e emancipadora.

Arrematamos o artigo, brindando o leitor com uma poesia que exprime com bastante similitude os processos de desconstrução e reconstrução que esse projeto nos oportunizou.

Há um tempo

Fernando Pessoa

Há um tempo em que é preciso abandonar as roupas usadas ...

Que já têm a forma do nosso corpo ...

E esquecer os nossos caminhos que nos levam sempre aos mesmos lugares...

É o tempo da travessia ...

E se não ousarmos fazê-la ...

Teremos ficado ... para sempre ...

À margem de nós mesmos... 


\section{Referências}

BAUMAN, Z.. (2012). Sobre educação e juventude: conversas com Riccardo Mazzeo. Rio de Janeiro: Zahar.

BERBEL, N. (2011). As metodologias ativas e a promoção da autonomia dos estudantes. Semina: Ciências Sociais e Humanas, Londrina, v. 32, n. 1, p. 25-40, jan./jun.

DEMO, P. (1998). Questões para a teleducação. Petrópolis, RJ: Vozes.

DEMO, P. (2009). Aprender bem/mal. Campinas-SP: Autores Associados.

DEWEY, J. (1959). Democracia e Educação. 3 ed. Tradução de Godofredo Rangel e Anísio Teixeira. São Paulo: Companhia Editora Nacional.

DEWEY, J. (1971). Experiência e educação. Tradução de Anísio Teixeira. São Paulo: Companhia Editora Nacional.

DIESEL, A.; BALDEZ, A. \& MARTINS, S. (2017). Os princípios das metodologias ativas de ensino: uma abordagem teórica. Revista Thema, 14(1), 268-288. DOI: https://doi.org/10.15536/thema.14.2017.268-288.404.

FREIRE, P. (1983) Extensão on Comunicação? Tradução de Rosisca Darcy de Oliveira. 7. ed. Rio de Janeiro: Paz e Terra.

FREIRE, P. (1992). Pedagogia da esperança: um reencontro com a pedagogia do um reencontro com a pedagogia do oprimido. Rio de Janeiro: Paz e Terra.

FREIRE, P. (1997) A importância do ato de ler: em três artigos que se complementam. 33. ed. São Paulo: Cortez.

FREIRE, P. (2001) Carta de Paulo Freire aos professores. Estudos avançados, São Paulo, v. 15, n. 42, p. 259-268.

FREIRE, P., FAUNDEZ, A. (1985). Por uma pedagogia da pergunta. Rio de Janeiro: Paz e Terra.

GADOTTI, M. (1995) Histórias das ideias pedagógicas. São Paulo: Ática.

MIZUKAMI, M. G. N. (1986). Ensino: as abordagens do processo. São Paulo: EPU.

ORGANIZAÇÃO PARA COOPERAÇÃO E DESENVOLVIMENTO ECONÔMICOS. Estudos da OCDE sobre competências. Competências para o progresso social: o poder das competências socioemocionais/OCDE. São Paulo: Fundação Santillana, 2015.

SAVIANI, D. (1991). Escola e democracia. 24. ed. São Paulo: Cortez.

SILVA, Rosimara Gomes da; PORTO, Humberta Gomes Machado. Educação Emocional, Pressupostos para a Escola e a Sociedade Pensarem na Perspectiva da Inteligência Emocional. Revista Cientifica Aprender, Minas Gerais, p. 235-240, 3 jun. 2019. Recuperado de http://revista.fundacaoaprender.org.br/?p=235, em 15 jun. 2020. 
THIOLLENT, M. (2009) Metodologia da pesquisa-ação. São Paulo: Cortez.

THIOLLENT, M. COLETTE, M. M. (2014). Pesquisa-ação, formação de professores e diversidade. Acta Scientiarum. Ciências Humanas e Sociais (em linea). 36 (2), 207-216. Recuperado de https://www.redalyc.org/articulo.oa?id=307332697009, em 11 fev. 2019.

\section{Sobre as Autoras}

\section{ADELINE ARAÚJO CARNEIRO FARIAS ${ }^{1}$}

ORCID: https://orcid.org/0000-0002-4373-7868

Doutora em Ciências Sociais pela UNISINOS, Mestre em Ciências pela UFRRJ, Especialista em Docência em Educação Profissional e Tecnológica pelo Centro Federal de Educação Profissional e Tecnológica de Roraima - CEFET/RR (2008), Especialista em Educação Interdisciplinar pelo Instituto Cuiabano de Educação (2003), graduada em Ciências Sociais pela Universidade Estadual do Ceará (1996) com habilitação em Pesquisa. Professora do Instituto Federal de Sergipe, lotada no Campus Aracaju. Atua no Ensino nas modalidades do Ensino médio integrado a Educação Profissional à pós-graduação. Desenvolve Projetos de Pesquisa e de Inovação no Ensino. Investe em metodologia ativa com ênfase na integração da pesquisa ao ensino, com base na pesquisa como princípio pedagógico. Realiza pesquisas nas áreas de Juventudes, Identidade e Educação Socioemocional.

adeline.farias@ifs.edu.br; adelinecarneiro@yahoo.com.br

\section{JOCELAINE OLIVEIRA DOS SANTOS ${ }^{2}$}

(D) ORCID: https://orcid.org/0000-0001-8457-0382

Professora da Educação Básica, Técnica e Tecnológica do Instituto Federal de Sergipe/ Campus Estância. Doutorado em Ciências Sociais pela UNISINOS, na área de Concentração Políticas e Práticas Sociais, linha de pesquisa Identidade e Sociabilidade. Mestrado em Letras pela Universidade Federal de Sergipe, na área de concentração Estudos da Linguagem e Ensino, linha de pesquisa Teorias do Texto UFS. Pós-graduação em Teorias do Texto pela Universidade Federal de Sergipe - UFS. Graduação em Letras Português pela Universidade Tiradentes - UNIT. jocelaine.santos@ifs.edu.br

\section{IARA VANESSA MAFRA BICHARA ${ }^{3}$}

D ORCID: https://orcid.org/0000-0002-2745-3195

Possui graduação em Letras - Português e Espanhol pela Universidade Federal do Amazonas(2011) e mestrado em Educação pela Universidade Federal Rural do Rio de Janeiro(2016). Atualmente é professora EBTT em exercício no Instituto Federal de Sergipe. Tem experiência na área de Letras, com ênfase em Línguas Estrangeiras Modernas.

iara.bichara@ifs.edu.br

Submetido: 11 ago. 2020

Aceito: 21 set. 2020 